\title{
Philip D. Lawley (1927-2011)
}

\section{Chemist who discovered that cancer is caused by damage to DNA.}

$\mathrm{P}$ hilip Lawley laid the foundation for the idea that cancer is a genetic disease. $\mathrm{He}$ provided the first convincing evidence that DNA is the key target for chemicals that cause cancer, and identified a major DNArepair mechanism that counteracts the assault of carcinogens on DNA.

Lawley, who died on 18 December 2011, was born in 1927 in the village of Abbots Bromley in Staffordshire, UK, to two teachers. He obtained a degree in chemistry in 1949 at the University of Oxford and moved to the University of Nottingham, where he studied the physicochemical properties of DNA (before its double-helical structure was revealed by James Watson and Francis Crick). His graduate work included the first investigation of what later became known as DNA denaturation (the separation of the macromolecule into two strands).

After gaining a PhD in 1953, Lawley took up a post at the Chester Beatty Research Institute (now the Institute of Cancer Research) in London, where he investigated the interaction of anticancer drugs with DNA. By 1957, he had demonstrated that alkylating agents could bond covalently with DNA to produce stable products (adducts), a radical idea at a time when it was believed that such interactions were weak or reversible and that proteins were the crucial target of carcinogens.

In the late 1950 s, with chemist Peter Brookes, Lawley carried out seminal studies on the binding of mutagens and carcinogens to DNA in living organisms. The Radiochemical Centre in Amersham had just begun producing radioactively labelled chemicals, including mustard gas, which had been used as a chemical weapon in the First World War. Ironically, Lawley's father had been exposed to it while serving in the trenches. Mustard gas was already known to be a mutagen and it was later found to cause lung cancer. It was the archetype of difunctional (having two chemically reactive sites) anticancer drugs, such as melphalan and chlorambucil, which were developed during the 1950s at the Chester Beatty.

To conduct these potentially hazardous studies, Lawley and Brookes moved out of London to the institute's Pollards Wood Research Station, which was set in 24 hectares of woodland and conveniently close to the Radiochemical Centre. In these leafy and peaceful surroundings, they produced their seminal work on the binding of mutagens and carcinogens to DNA. In 1960, they reported that mustard gas formed adducts with guanine in DNA, in viruses, bacteria, cultured mouse cancer cells and cancers in mice.

The adduct hindered DNA replication and cell division by crosslinking the strands of the DNA helix, thus explaining mustard gas's extraordinary toxicity to cells. They demonstrated that bacteria resistant to

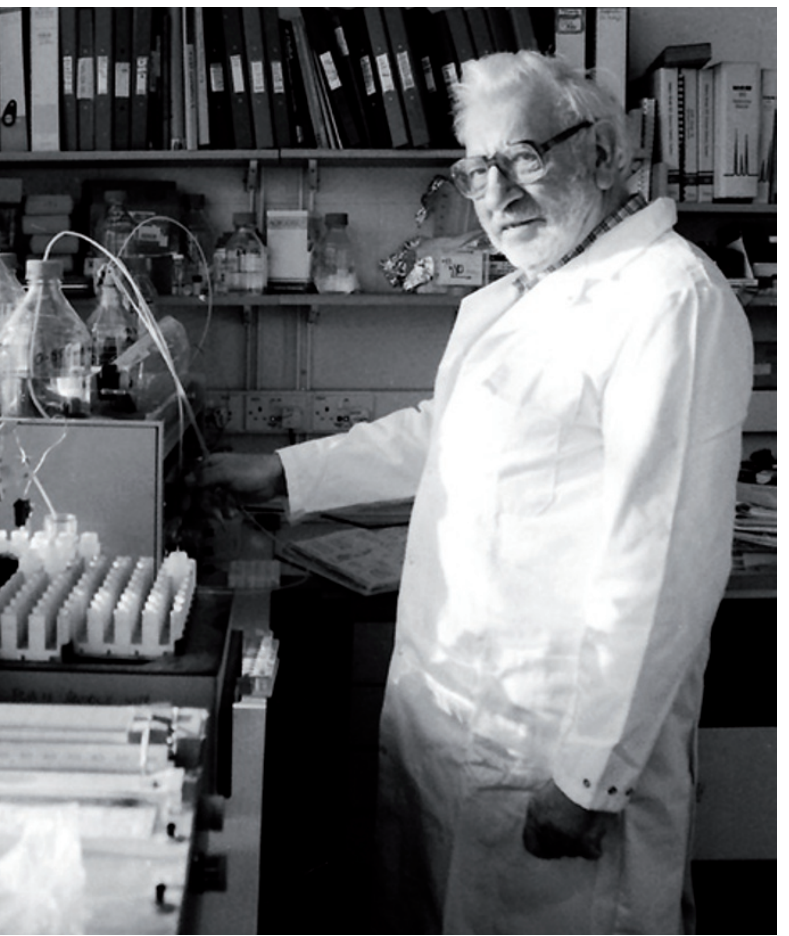

mustard gas used enzymes to remove those crosslinks, but sensitive bacteria did not. This was the first convincing evidence for the repair of DNA adducts in a living organism. It is now clear, 50 years on, that many of the genes mutated in human cancer are involved in DNA repair.

In a second landmark paper in 1964 , Lawley and Brookes reported in Nature a correlation between carcinogenicity and DNA binding, using radioactively labelled polycyclic aromatic hydrocarbons (PAHs) applied to mouse skin. These ubiquitous products of incomplete combustion (found, for example, in tobacco smoke) are chemically inert, but many are potent carcinogens when metabolically activated. Lawley and Brooks found that the amount of binding to DNA, but not to protein or RNA, increased with the carcinogenic potency of the PAHs. This discovery overturned the prevailing view that proteins were the critical cellular targets for carcinogens and it changed the course of cancer research.

Lawley went on to show how point mutations are induced when potent alkylating mutagens (such as $N$-methyl- $N$-nitrosourea) react with those atoms in DNA that determine base-pairing during DNA replication. Point mutations are now known to occur frequently in a variety of human cancer genes. He also discovered the 6-O-methylguanine-DNA methyltransferase DNA-repair system that selectively removes such modified DNA bases.

Outwardly shy, Lawley had a wry sense of humour, liberal views and enormous integrity. He did not follow scientific fashion and was happiest working at the bench. He took extraordinary pleasure in conversation, which was enriched by his passions for books, jazz, art, dogs and old trams. He often engaged in protracted and sometimes heated debate with whoever happened to be around - usually a scientific colleague, but occasionally an innocent bystander - sometimes losing track of time. At Pollards Wood, these conversations would often continue al fresco in the coppiced beech woods, sometimes in the company of Lawley's whippet.

Lawley retired in 1992, but continued to work in the Institute of Cancer Research laboratories at Sutton in south London for many more years, enhancing the lives of those who worked alongside him with his knowledge, congeniality and wit. Fittingly, in January 2003, the institute honoured Brookes and Lawley by naming a $£ 21$-million (US\$32-million) laboratory in Sutton after them. -

Stanley Venitt is honorary associate and David H. Phillips is professor of environmental carcinogenesis in the Analytical and Environmental Sciences Division, King's College, London SE1 9NH, UK. Both were colleagues of Philip Lawley at the Institute of Cancer Research. e-mail:stan.venitt@kcl.ac.uk 